\title{
Propriospinal Circuitry Underlying Interlimb Coordination in Mammalian Quadrupedal Locomotion
}

\author{
Laurent Juvin, John Simmers, and Didier Morin \\ Laboratoire de Physiologie et Physiopathologie de la Signalisation Cellulaire, Centre National de la Recherche Scientifique, Unité Mixte de Recherche 5543, \\ Equipe Neurophysiologie Adaptative des Systèmes Moteurs, 33076 Bordeaux, France
}

\begin{abstract}
Soon after birth, freely moving quadrupeds can express locomotor activity with coordinated forelimb and hindlimb movements. To investigate the neural mechanisms underlying this coordination, we used an isolated spinal cord preparation from neonatal rats. Under bath-applied 5-HT, $N$-methyl-D,L-aspartate (NMA), and dopamine (DA), the isolated cord generates fictive locomotion in which homolateral cervicolumbar extensor motor bursts occur in phase opposition, as does bursting in homologous (left-right) extensor motoneurons. This coordination corresponded to a walking gait monitored with EMG recordings in the freely behaving animal. Functional decoupling of the cervical and lumbar generators in vitro by sucrose blockade at the thoracic cord level revealed independent rhythmogenic capabilities with similar cycle frequencies in the two locomotor regions. When the cord was partitioned at different thoracic levels and 5-HT/NMA/DA was applied to the more caudal compartment, the ability of the lumbar generators to drive their cervical counterparts increased with the proportion of chemically exposed thoracic segments. Blockade of synaptic inhibition at the lumbar level caused synchronous bilateral lumbar rhythmicity that, surprisingly, also was able to impose bilaterally synchronous bursting at the unblocked cervical level. Furthermore, after a midsagittal section from spinal segments $\mathrm{C} 1$ to $\mathrm{T} 7$, and during additional blockade of cervical synaptic inhibition, the cord exposed to 5-HT/NMA/DA continued to produce a coordinated fictive walking pattern similar to that observed in control. Thus, in the newborn rat, a caudorostral propriospinal excitability gradient appears to mediate interlimb coordination, which relies more on asymmetric axial connectivity (both excitatory and inhibitory) between the lumbar and cervical generators than on differences in their inherent rhythmogenic capacities.
\end{abstract}

Key words: locomotion; neuronal network interactions; newborn rat; spinal cord; forelimb; hindlimb; in vitro

\section{Introduction}

The production of most rhythmic behaviors relies on the autoactivity of localized networks of neurons or central pattern generators (CPGs) within an animal's nervous system (Marder and Calabrese, 1996; Stein et al., 1997). The CPGs responsible for quadrupedal locomotion in vertebrates, for example, reside as half-center modules in the cervical and lumbar regions of the spinal cord, each generating basic motor output patterns responsible for rhythmic contractions of antagonistic flexor-extensor groups of muscles in the corresponding forelimb or hindlimb (Grillner, 1981).

The orchestration of effective locomotor behavior not only demands a strict temporal relationship between the spinal CPG circuits controlling the different limbs and other body regions but also the capacity for rapid alterations in network coupling

Received Feb. 21, 2005; revised May 9, 2005; accepted May 10, 2005.

This work was supported by grants from the Conseil Régional d'Aquitaine/Fonds Européens de Développement Régional and the Fondation pour la Recherche Médicale. L.J. was supported by the Demain Debout and the Institut pour la Recherche sur la Moelle épinière et l'Encéphale. We thank Tiffany Aubert for assistance with our in vivo experiments and Dr. J.-R. Cazalets for helpful discussions and comments on this manuscript.

Correspondence should be addressed to Dr. Didier Morin, Université Victor Segalen Bordeaux 2, Centre National de la Recherche Scientifique, Unité Mixte de Recherche 5543, Laboratoire Physiologie et Physiopathologie de la Signalisation Cellulaire, bātiment 2A, 146 rue Léo Saignat, 33076 Bordeaux Cedex, France. E-mail: didier.morin@umr5543.u-bordeaux2.fr.

DOI:10.1523/JNEUROSCI.0696-05.2005

Copyright $\odot 2005$ Society for Neuroscience $\quad$ 0270-6474/05/256025-11\$15.00/0 that allow changes in interlimb coordination appropriate for activities such as walking, running, and swimming. A precise understanding of the neural basis of multilimb behaviors such as tetrapod locomotion therefore requires knowledge of the mechanisms and cellular pathways by which the various underlying central neuronal circuits interact through both transverse and longitudinal neuronal coupling systems.

Although considerable data are now available on the neural substrates of bilateral limb coordination, particularly of lumbar spinal circuits controlling the hindlimbs of quadruped mammals (Kjaerulff and Kiehn, 1996; Rossignol, 1996; Kremer and LevTov, 1997; Cazalets and Bertrand, 2000; Butt et al., 2002), relatively little is known of the propriospinal processes that couple the forelimbs and hindlimbs (Viala and Vidal, 1978; English, 1979, 1989), which allow the switch between different modes of rostrocaudal coordination. Major problems in this respect include the identification of different neuronal pathways involved in coordinating and establishing their specific roles as well as deciphering the relationship between modes of coupling and the balance between processes of synaptic excitation and inhibition.

The in vitro neonatal rat spinal cord preparation has become established as an excellent model for studying the neuronal correlates of mammalian locomotion (Kiehn and Butt, 2003). For more than one decade, this reduced preparation has been widely used to investigate the origin and mechanisms principally of lum- 
bar network activity responsible for rhythmic hindlimb movements (Cazalets et al., 1992, 1995; Kjaerulff and Kiehn, 1996). Moreover, with this preparation, the spinal localization of the forelimb locomotor generators has been reported, along with initial data on the functional relationship between cervical and lumbar networks (Ballion et al., 2001). Here, locomotor-related burst patterns recorded from the motor roots of rhythmically active isolated cords were compared with patterns of interlimb coordination in the freely behaving animal. Split-bath experiments in combination with pharmacological manipulation and cord lesions were then used to determine the nature of propriospinal interactions between the cervical and lumbar locomotor CPGs. Our results demonstrate that coordination is mediated by a powerful ascending phasic influence that accrues caudorostrally through activation of intervening thoracic cord segments to couple cervical rhythmogenesis to that of the lumbar region. Moreover, this coupling drive is mediated by the concerted actions of ascending excitation and inhibition. Some of this work has appeared previously in abstract form (Juvin et al., 2003).

\section{Materials and Methods}

In vivo experiments. Newborn rats (Wistar; 3-7 d of age) from different litters were obtained from timed pregnant female rats raised in our laboratory breeding center. Animals were anesthetized by hypothermia until the loss of reflex responsiveness to tail pinching. Pairs of $50 \mu \mathrm{m}$ silver wires for electromyography (EMG) were then inserted into extensor limb muscles (triceps and gastrocnemius of the forelimb and hindlimb, respectively) and maintained by means of tissue glue (collodion; Sigma, Lyon, France). To limit the discomfort of the animals and to facilitate locomotor movements, a maximum of three pairs of recording electrodes was used to examine both left-right and anteroposterior coordination. Animals were then warmed, and the temperature of the recording set up was maintained at $\sim 37^{\circ} \mathrm{C}$ by means of spotlights.

To induce overground locomotion, a hollow cone filled with bedding material from the neonate's nest was positioned in front of the animal's muzzle. This device, which exudes a powerful olfactory stimulus (Jamon and Clarac, 1998), was then pulled slowly over a distance of $50 \mathrm{~cm}$ to elicit EMG-recorded episodes of locomotion. All experiments were performed in accordance with the European Communities Council Directive.

In vitro spinal cord preparations. In vitro experiments were performed on isolated preparations of the spinal cords of 0- to 4-d-old rats. After anesthesia by hypothermia, animals were decapitated and eviscerated. The skin and muscles were rapidly removed and then preparations were placed in a $25 \mathrm{ml}$ chamber containing artificial CSF (aCSF; see composition below) maintained at $10^{\circ} \mathrm{C}$ throughout the dissection (flow rate, $5-10 \mathrm{ml} / \mathrm{min}$ ). The dissection was continued under binocular microscopy to isolate gently the entire spinal cord with its ventral roots still attached. The preparation was then placed in a $10 \mathrm{ml}$ recording chamber and pinned down with its ventral surface upwards. Preparations were superfused continuously (flow rate, $3-5 \mathrm{ml} / \mathrm{min}$ ) with aCSF equilibrated with $95 \% \mathrm{O}_{2} / 5 \% \mathrm{CO}_{2}$, pH 7.4, containing the following (in $\mathrm{mm}$ ): 113 $\mathrm{NaCl}, 4.5 \mathrm{KCl}, 1 \mathrm{NaH}_{2} \mathrm{PO}_{4}, 2 \mathrm{CaCl}_{2}, 1 \mathrm{MgCl}_{2}, 25 \mathrm{NaHCO}_{3}$, and 11 D-glucose. The temperature of this aCSF was progressively raised to $22-$ $25^{\circ} \mathrm{C}$ before recording procedures began.

In most preparations, the recording chamber was partitioned into two (or three, in the case of sucrose block experiments; see below) bath chambers with independent perfusion systems. Narrow petroleum jelly bridges allowed the cord to remain functionally intact between the different compartments, and water tightness was checked at the end of each experiment by adding dye (Fast Green; Sigma) to the bathing medium on either side of a given bridge. Spinal ventral root activity was recorded using glass suction electrodes or Vaseline (Prolabo, Fontenay Sous-Bois, France)-insulated, stainless-steel pin electrodes. Signals were amplified $(10,000 \times)$ by homemade AC amplifiers, bandpass-filtered $(0.1-3 \mathrm{kHz})$, full-wave rectified, integrated (sample rate, $3 \mathrm{kHz} ; \tau=100 \mathrm{~ms}$ ), digitized, and stored on a computer hard disk (Spike2 software; Cambridge Electronic Design, Cambridge, UK) for off-line analysis.
Drug application. Pharmacological substances were bath-applied at least $30 \mathrm{~min}$ after the end of dissection by means of gravity supply. A mixture of $N$-methyl-D,L-aspartate (NMA; $0.5-2 \times 10^{-5} \mathrm{M}$ ), serotonin $\left(5-\mathrm{HT} ; 10^{-5} \mathrm{M}\right)$, and dopamine (DA; $\left.10^{-4} \mathrm{M}\right)$ was used to elicit prolonged and robust episodes of fictive locomotion (Barrière et al., 2004). A combination of the GABAergic antagonist bicuculline (BIC; $0.25 \times 10^{-5}$ $\mathrm{M})$ and the glycinergic antagonist strychnine (STR; $\left.0.25 \times 10^{-5} \mathrm{M}\right)$ was used to block inhibitory synapses. In an additional series of experiments, the lumbar spinal cord was isolated reversibly from the cervical region using a sucrose block of axonal conduction in the thoracic spinal segments. For this, the recording chamber was partitioned into three baths, and the intermediate thoracic cord compartment (containing at least four contiguous spinal segments) was perfused with an isotonic sucrose solution (339 $\mathrm{mm}$ in distilled water) buffered with HEPES (5 mM) and adjusted to $\mathrm{pH} 7.4$ using $\mathrm{NaOH}$ solution. All drugs used in these in vitro experiments were purchased from Sigma.

Lesion experiments. In some experiments, the spinal cord was transected at the thoracic level to separate physically cervical and lumbar spinal cord regions. In other experiments, sagittal splitting was performed to separate the two sides of the cord. In all cases, lesions were performed with a razor blade fragment, and a control period of $45 \mathrm{~min}$ was respected before data were collected.

Data analysis. Spontaneous and induced rhythmic motor bursts were characterized in terms of their mean duration over $\geq 20$ integrated cycles that were selected randomly from a recorded sequence. The integrated transform was then used to evaluate real or fictive locomotor cycle period and the phase relationship between ipsilateral and contralateral motor nerves or muscle discharges. Duty cycles (burst duration/cycle period) of cervical and lumbar rhythmic activities were then evaluated and normalized as a percentage. Statistical values were expressed as means \pm SEM. Differences between means were analyzed using a statistical software package (SigmaStat for Windows; SPSS, Chicago, IL) and assessed either by Student's $t$ test or one-way ANOVA with a Tukey posttest. Unless otherwise specified, changes in mean values for each parameter were taken to be significant at $p<0.05$.

In several experimental series, the expression of stable rhythmicity in ventral motor root discharge was assessed by autocorrelation analysis taken at 120-190 s of activity. Similarly, the coordination between the activities of different ventral roots was examined by means of crosscorrelation analysis of $\geq 120 \mathrm{~s}$ of activity. The resultant correlograms were plotted with $95 \%$ (means \pm 2 SEM) confidence intervals that were calculated using Statistica 6 software (Statsoft, Tulsa, OK). Crosscorrelations coefficients between two locomotor outputs allowed estimation of coupling strength whereby values approaching 1 indicated synchrony, whereas values toward -1 reflected burst alternation. A flat cross-correlogram at $\sim 0$ indicated independent rhythms.

\section{Results}

\section{Overground locomotion}

Initially, electromyographic recordings of forelimb elbow (triceps) and hindlimb ankle (gastrocnemius) extensor muscles were performed in freely moving neonates $(n=5)$ (Fig. 1 A1) to allow comparison of interlimb coordination during actual locomotion with fictive locomotor patterns subsequently observed in the main in vitro part of our study. During the first postnatal week (3-7 d), spontaneous locomotor episodes are less frequent than in older animals, mainly because of the immaturity of postural control at this age (Jamon and Clarac, 1998). To circumvent this problem, newborn rats were trained to follow a moving olfactory stimulus (see Materials and Methods), which elicited stable sequences of locomotion in which the basic pattern of limb extensor activity consisted of a clear left-right (homologous limbs) and anteroposterior (homolateral limbs) alternation (mean phase, $0.48 \pm 0.02$ and $0.59 \pm 0.04$, respectively; mean cycle period, $1.22 \pm 0.03 \mathrm{~s}$; mean burst duration, $0.73 \pm 0.02 \mathrm{~s} ; n=5$ animals) (Fig. 1A1,A2) (Brocard et al., 1999; Navarrete et al., 2002). Contralateral forelimb and hindlimb extensor muscle activity (i.e., in 


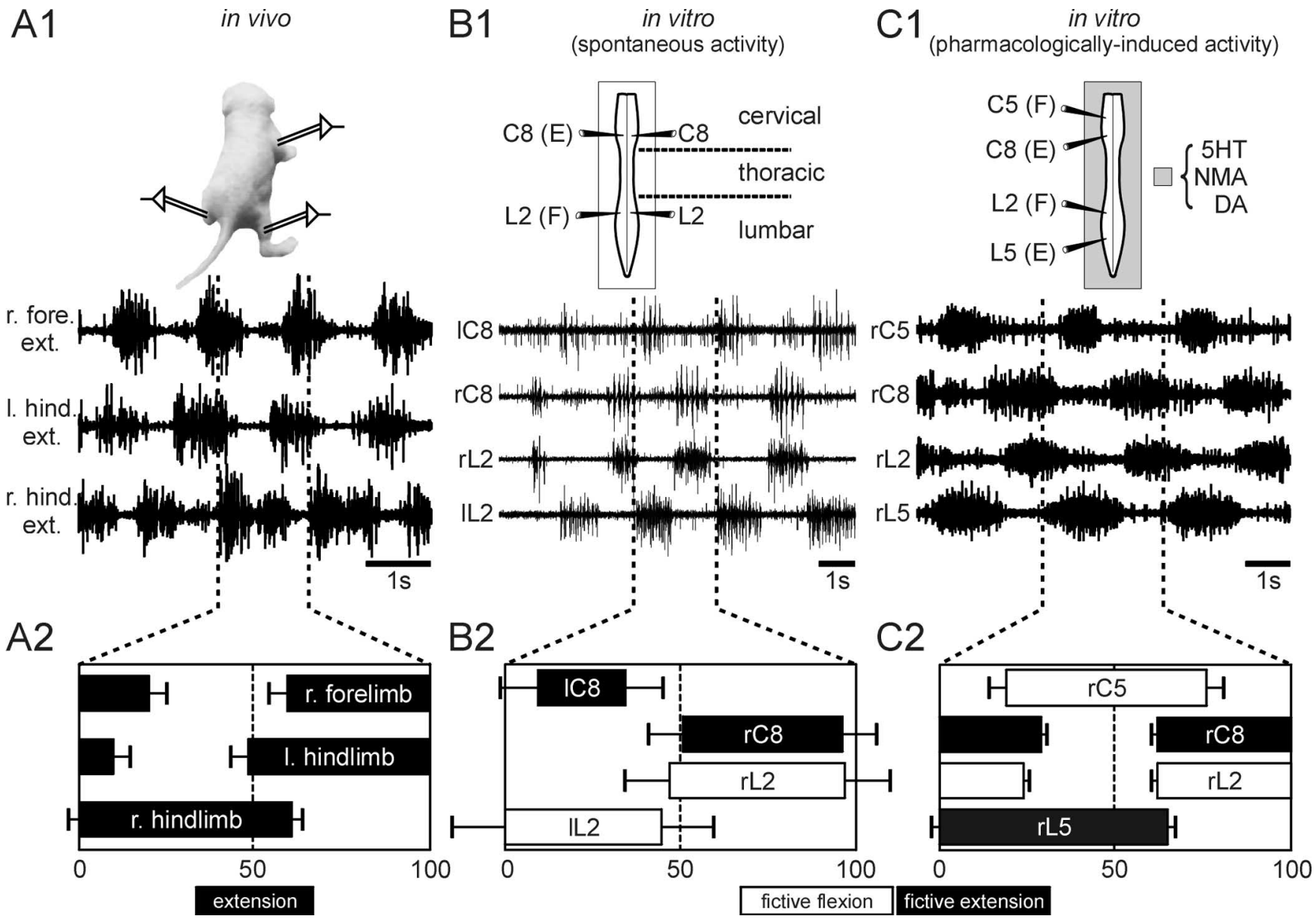

Figure 1. Motor pattern generation for walking in neonatal rat (3-7 d of age) spinal cord. A1, Electromyographic recordings of right forelimb (r. fore.) and bilateral hindlimb (I. and $\mathrm{r}$. hind.) extensor muscles (ext.) during overground locomotion. A2, Phase diagram showing a single normalized locomotor cycle with onset and offset ( \pm SEM as horizontal lines) of extensor EMG activity expressed as a percentage (5 animals). B, C, In vitro spinal cord preparation used to study coordination between spinal rhythm-generating circuitry during spontaneous (B1) and pharmacologically induced (C1) fictive locomotion. Extracellular recordings were made simultaneously from indicated cervical (C) and lumbar (L) ventral roots. In C1, stable episodes of fictive locomotion were evoked by perfusion of a saline containing serotonin $\left(5-\mathrm{HT} ; 10^{-5} \mathrm{M}\right)$, NMA $\left(10^{-5} \mathrm{M}\right)$, and DA $\left(10^{-4} \mathrm{M}\right) . \mathbf{B 2}, \mathrm{C} 2$, Phase diagrams (as in A2) illustrating "fictive gaits" corresponding to walking during spontaneous (B2; from 1 preparation) and pharmacologically induced (C2; from 18 preparations) rhythmicity. E, Extensor; $F$, flexor; r, right; l, left.

diagonal limbs) showed a high degree of in-phase coordination (phase difference in burst onset, $11.1 \pm 4.8 \%$ ) (Fig. 1A2), consistent with both a walking gait (Orlovsky et al., 1999) and a limb coordination previously observed during free swimming in newborn rats (Bekoff and Trainer, 1979).

\section{Locomotor rhythmicity and "fictive walking"}

We next wished to determine whether the neuronal correlates of this pattern of interlimb coordination observed in the behaving animal is also expressed by locomotor circuits in the in vitro spinal cord. Under control saline conditions, such isolated preparations in which simultaneous recordings were made from cervical (C) and lumbar (L) ventral motor roots that normally innervate muscles of the forelimbs and hindlimbs, respectively, occasionally displayed short ( $\leq 10 \mathrm{~s}$ ) episodes of spontaneous locomotor-like activity in a very small number of experiments (2 from 30 preparations measured) (Fig. 1B1). This rare spontaneous motor bursting, which presumably had a physiological relevance because it involved neurotransmitter release and actions that were endogenous to the spinal cord, was nonetheless well coordinated, showing a strict left-right alternation (mean period, $2.04 \pm 0.13 \mathrm{~s}$; mean burst duration, $0.83 \pm 0.04 \mathrm{~s} ; n=64$ motor bursts measured from one spontaneously active preparation). In accordance with our in vivo observations, ipsilateral cervical extensor (C8) and lumbar flexor (L2) motoneurons tended to be synchronously active (Fig. $1 \mathrm{~B} 2$ ). Note that motoneurons in $\mathrm{C} 8$ innervate forelimb extensor muscles, including the upper limb triceps, whereas axons in L2 innervate predominately hindlimb flexor muscles (see below).

In a large majority of preparations (28 of 30), however, the isolated spinal cord remained quiescent under control saline. In these cases, bath application of a mixture of NMA $\left(10^{-5} \mathrm{M}\right)$, 5-HT $\left(10^{-5} \mathrm{M}\right)$, and DA $\left(10^{-4} \mathrm{M}\right)$ almost always elicited sustained episodes of fictive locomotion (Fig. 1C1) (Barrière et al., 2004). In the presence of this neuromodulator mixture, the rhythmic motor activity expressed, which was very similar to the in vivo and spontaneous in vitro burst patterns described above, remained well coordinated and extremely stable (mean cycle period, $3.00 \pm 0.12 \mathrm{~s}$; mean burst duration, $1.82 \pm 0.14 \mathrm{~s}$; 18 preparations measured). The alternating rhythm recorded from homolateral C5 and C8 ventral roots (corresponding to the scapular girdle region), which have been identified previously as carrying flexor and extensor motor outputs, respectively (McKenna et al., 2000), is considered to be a close reflection of the operation of the cervical spinal generators engaged in forelimb locomotor movements (Ballion et al., 2001). Similarly, motor activity recorded from 

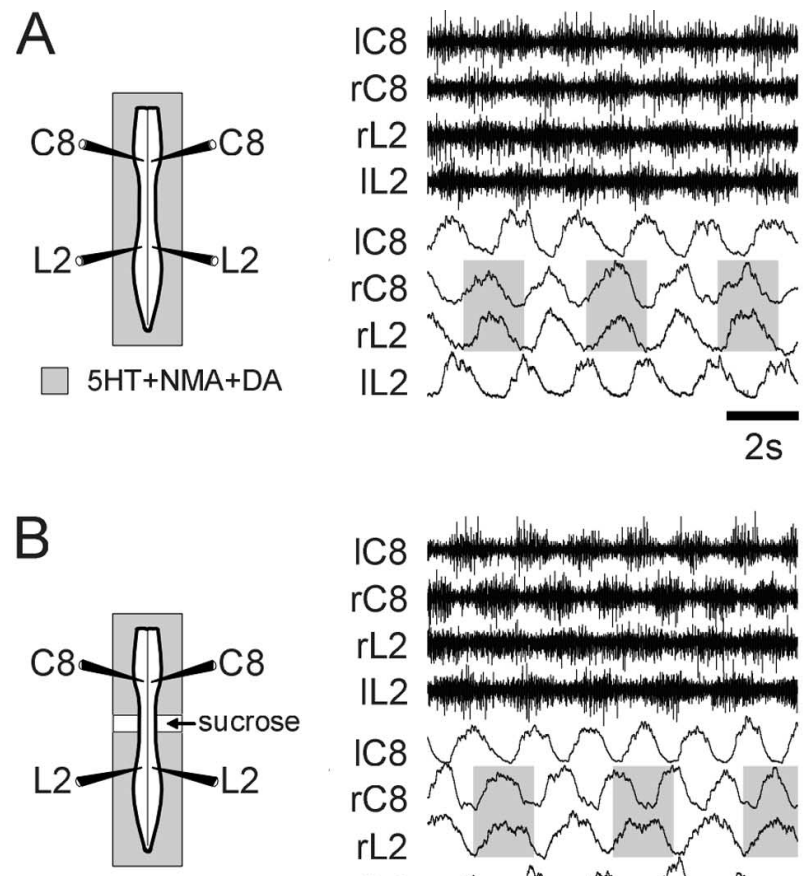

$5 \mathrm{HT}+\mathrm{NMA}+\mathrm{DA}$

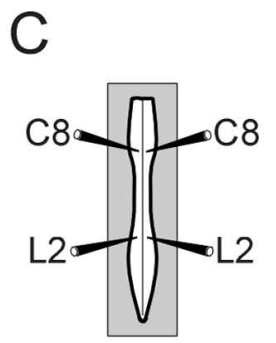

$5 \mathrm{HT}+\mathrm{NMA}+\mathrm{DA}$
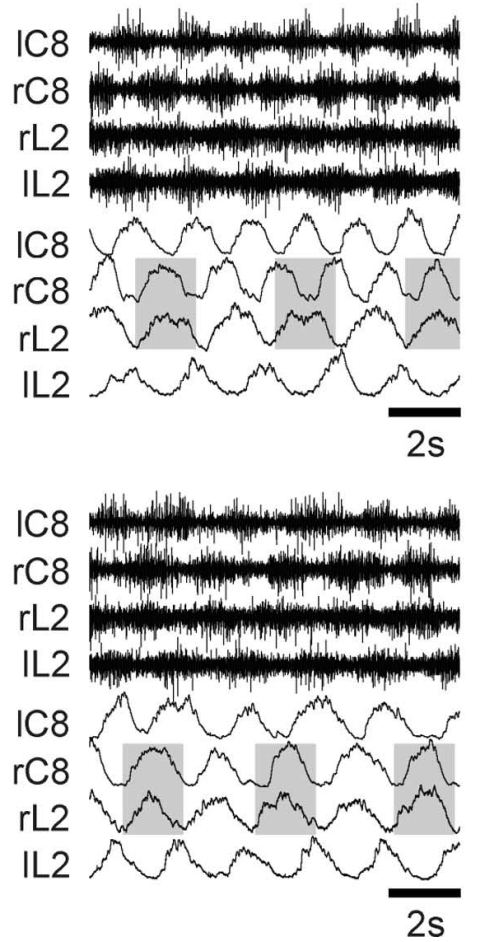
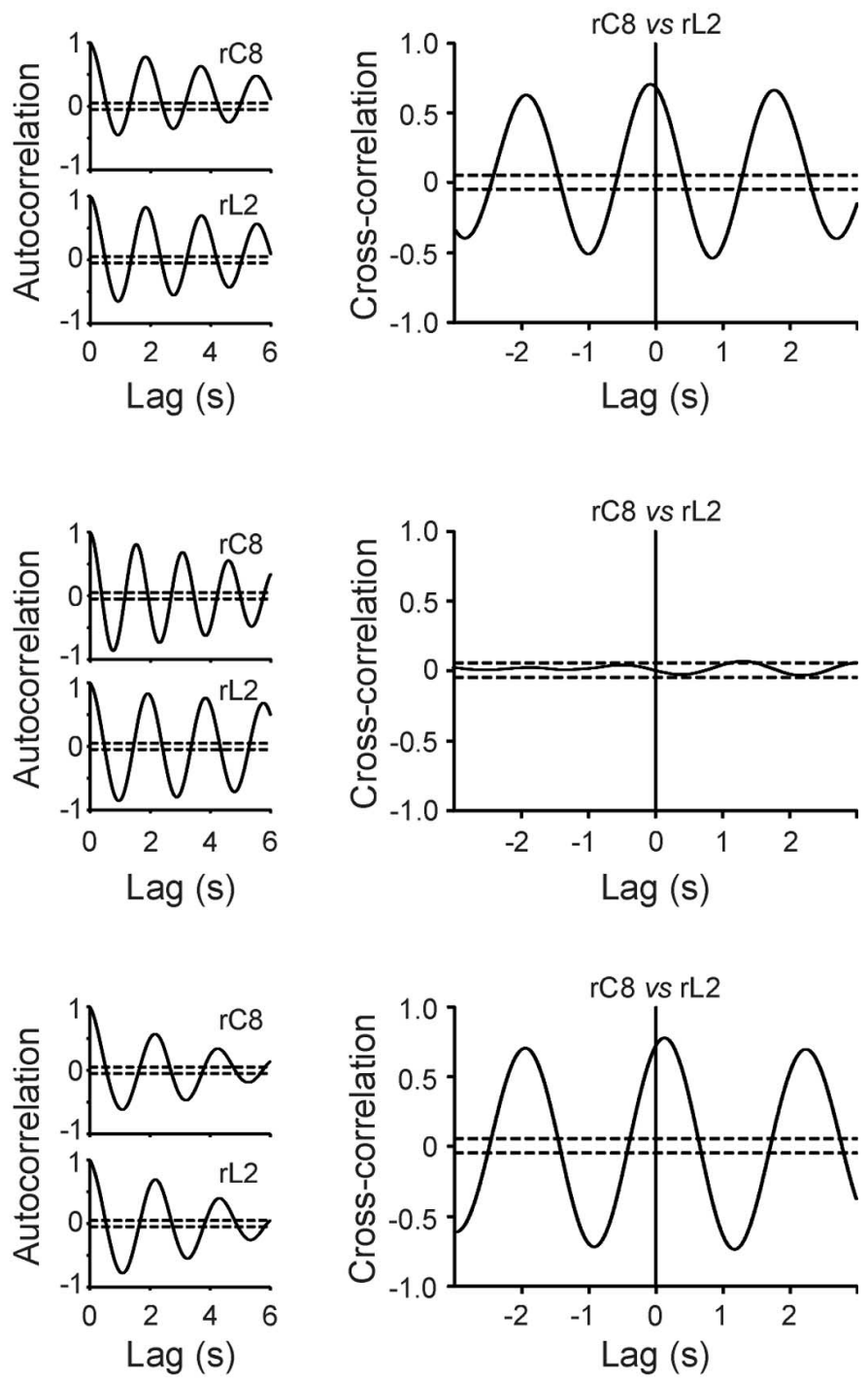

Figure 2. Effect of isotonic sucrose blockade of thoracic cord segments on cervical and lumbar locomotor rhythmicity. $A$, Left, Schematic of experimental procedure. Middle, Raw extracellular and integrated activity from cervical (bilateral (8) and lumbar (bilateral L2) ventral roots during 5-HT/NMA/DA-induced fictive locomotion. Right, Respective autocorrelograms of rectified data recorded from right (8 and right L2 ventral roots and cross-correlation between homolateral C8 and L2 activity showing an in-phase relationship (indicated by a positive cross-correlation coefficient at lag 0 ) in control conditions. Correlograms were computed from 120 to 190 s of activity and are superimposed with $95 \%$ ( \pm 2 SEM) confidence intervals (dashed lines). B, Loss of rostrocaudal coordination after sucrose block of thoracic segments (schematic to the left). Same presentation as in $\boldsymbol{A}$. Note that, despite decoupling (indicated by near flat cross-correlogram), both cervical and lumbar generators continued to operate at regular (see autocorrelograms) and similar (see Fig. $3 A$ ) frequencies. C, Recovery of control in-phase anteroposterior coordination after removal of sucrose blockade.C, Cervical ventral root; L, lumbar ventral root.

the homolateral L2 and L5 ventral roots, which respectively carry hindlimb flexor and extensor motor axons in the pelvic girdle region, is produced by the lumbar CPGs responsible for hindlimb locomotor movements (Kjaerulff and Kiehn, 1996). The burst-phase relationships within the activity pattern recorded from these different homolateral spinal roots invariably showed an out-of-phase coordination between flexor (C5 vs L2) and extensor (C8 vs L5) motor bursts of the two girdles (Fig. 1C2). These results therefore support the conclusion that despite the lack of sensory or brainstem inputs, the isolated cord of neonatal rat can reliably produce a motor pattern that corresponds to an interlimb coordination appropriate for quadrupedal walking or swimming (Fig. 1, compare B2-C2 and A2).

Propriospinal coupling between cervical and lumbar central pattern generators

The persistence of a well-coordinated fictive locomotor pattern in the in vitro spinal cord clearly indicates that quadrupedal limb coordination is, to a large extent, mediated by propriospinal connections between the cervical and lumbar generators. To determine the nature of these central pathways, sucrose blockade of axonal conduction in thoracic segments (see Materials and Methods) was used to disconnect reversibly the anterior and posterior spinal generators to evaluate both their intrinsic rhythmogenic capacities and the role of any reciprocal coordinating influences (Fig. 2). Within $20 \mathrm{~min}$ of sucrose application to thoracic segments in all seven preparations tested, the cervical and lumbar locomotor-like rhythms, which were highly regular (revealed by autocorrelation analysis) and previously tightly coordinated (see cross-correlations) under 5-HT/NMA/DA perfusion (Fig. 2A), became completely independent (Fig. $2 \mathrm{~B}$, right, statistically flat cross-correlogram), with each rhythm maintaining a strict bilateral alternation. Moreover, the decoupled rhythms in L2 and C8 remained stable (Fig. $2 B$, autocorrelograms) with cycle periods $(3.49 \pm 0.57$ and $2.68 \pm 0.69 \mathrm{~s}$, respectively) that were not signif- 
A

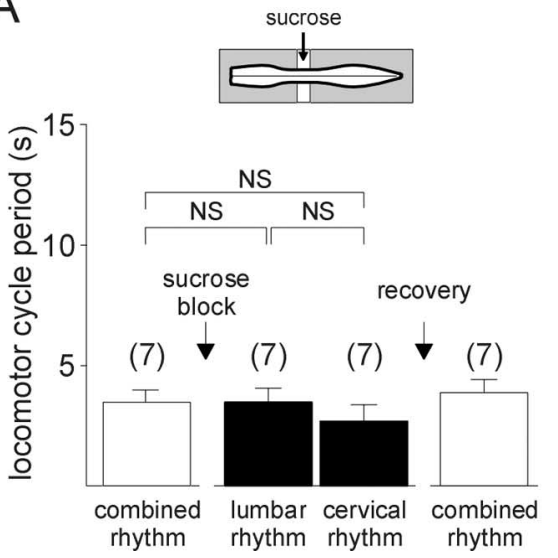

B

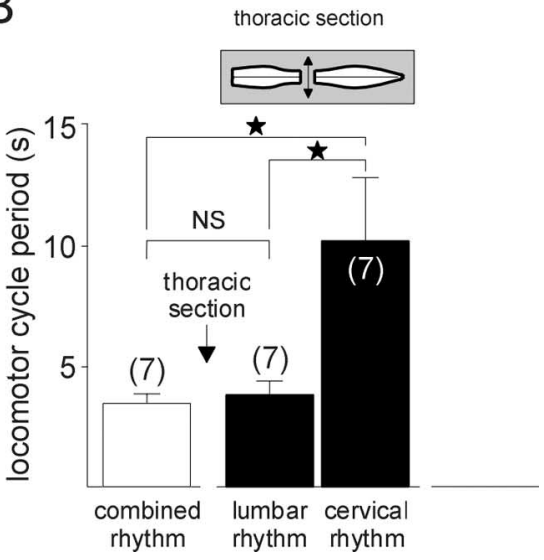

Figure 3. Histograms of combined lumbocervical locomotor cycle periods (mean values $\pm S E M$ ) in intact cord (open bars) and of independent lumbar and cervical periods (filled bars) during reversible sucrose blockade of thoracic cord ( $\boldsymbol{A}$ ) and after cord (at T7) transection $(\boldsymbol{B})$. As indicated by the schematics at the left, $\boldsymbol{A}$ is from the same experiments as in Figure 2 and $\boldsymbol{B}$ is from a different series of experiments. Numbers of measured preparations are indicated in parentheses. ${ }^{\star} p<0.05$. NS, Not significantly different.

icantly modified by lumbocervical separation (Fig. $3 A$ ). The original anteroposterior coordination was restored within minutes of removing the sucrose blockade in all seven experiments (Figs. 2C, $3 A$ ). These results therefore suggest that the cervical and lumbar locomotor generators share similar intrinsic rhythmogenic capacities (at least in the presence of exogenous 5-HT/NMA/DA) and that neither regional circuit can be considered as the pacemaker leader in their anteroposterior coupling.

These findings, with thoracic cord sucrose blockade, differ from the results of another series of experiments $(n=7)$ in which the cervical and lumbar regions were separated by a complete thoracic cord transection (Fig. 3B) (Ballion et al., 2001), in which experiments were performed on 5-HT/NMDA-activated spinal cords with the brainstem still present. After sectioning the cord (at T7), the burst period in $\mathrm{L} 2(3.83 \pm 0.56 \mathrm{~s})$ remained similar to the period of the single coordinated rhythm $(3.49 \pm 0.41 \mathrm{~s})$ recorded before the lesion, but the burst period in $\mathrm{C} 8$ was now significantly increased to $10.23 \pm 2.65 \mathrm{~s}$ $(p<0.05)$ (Fig. 3B), and C8 burst durations were substantially increased (data not shown) (see Discussion).

Existence of a caudorostral connectivity gradient between spinal generators

To explore the neural processes involved in interlimb coordination, the isolated cord was partitioned with a simple Vaseline barrier placed at different thoracic levels to allow differential perfusion of the posterior and anterior cord regions. A total of 25 preparations were used for these experiments, including seven cords with which separate trials were performed with different barrier positions. In control conditions in all cases, both cervical and lumbar generators were first activated by exposure of the entire cord to 5-HT/NMA/DA (Fig. $4 A 1)$. When the mixture was applied selectively to the cord caudal to T10-11 ( $n=13$ experiments), alternate bursting was now systematically induced in bilateral L2 ventral roots (Fig. 4A2), but in most cases, the $\mathrm{C} 8$ ventral roots remained silent (Fig. $4 \mathrm{~B}$ ), with only three preparations (23\%) expressing coordinated lumbocervical rhythmicity. However, the more rostral the placement of the thoracic barrier, the higher the proportion of preparations producing such coordinated lumbocervical bursting during selective caudal exposure to $5-\mathrm{HT} / \mathrm{NMA} / \mathrm{DA}$ [4 of 10 preparations $(40 \%)$ with barrier at T4-7; all nine preparations (100\%) with a

\section{$5 \mathrm{HT}+\mathrm{NMA}+\mathrm{DA}$}
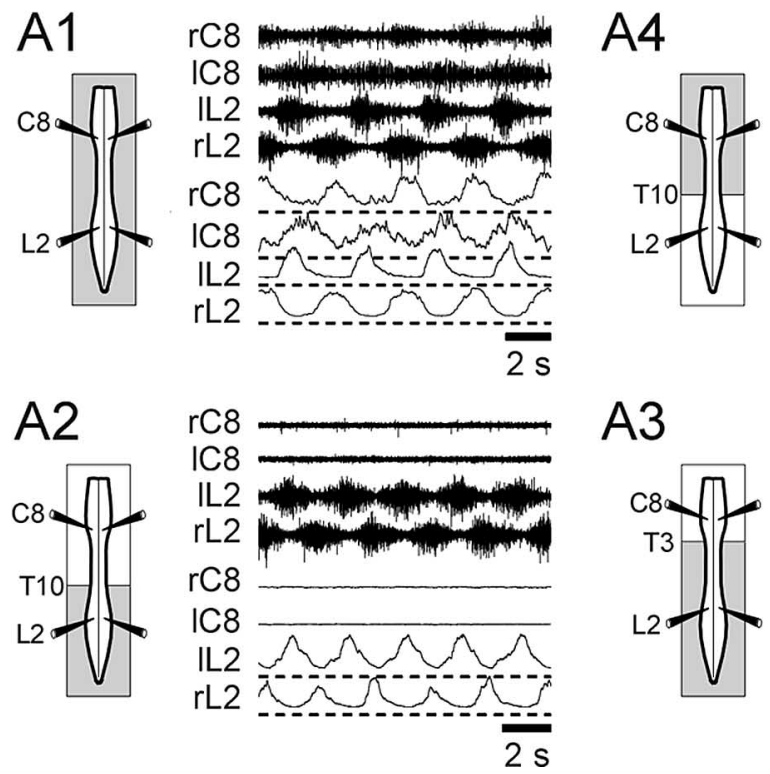

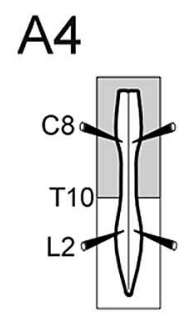

normal saline
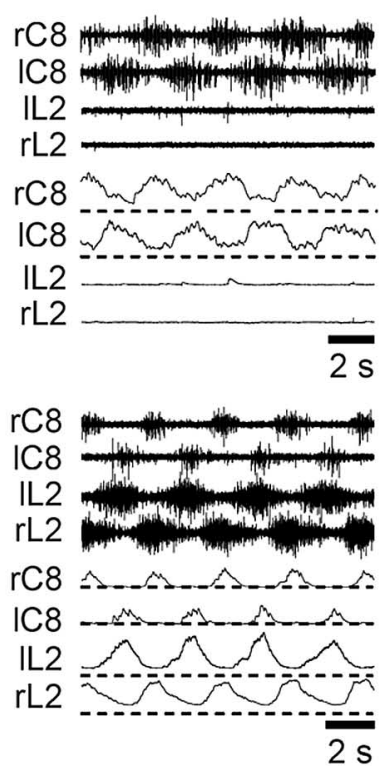

B

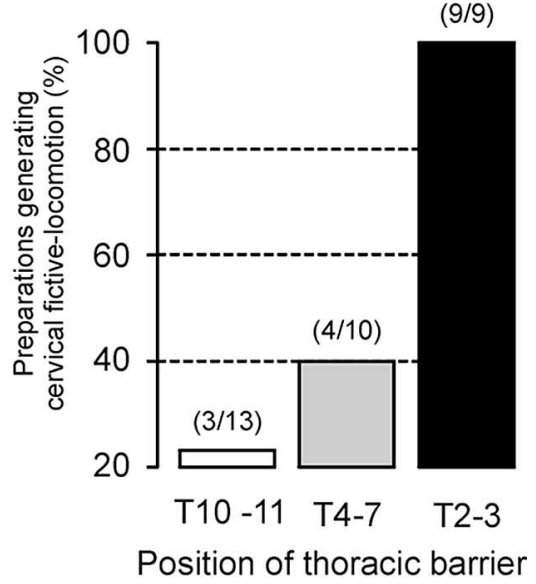

Figure 4. Ability of lumbar generators to drive cervical locomotor rhythmicity. $\boldsymbol{A}$, Raw extracellular and integrated cervical (bilateral (8) and lumbar (bilateral L2) ventral root activity from the same preparation during application of 5-HT/NMA/DA to the whole cord ( $\boldsymbol{A}$; ; control conditions) and to the spinal region caudal to T10 (A2), caudal to T3 (A3), and then rostral to T10 (A4). Dashed lines below each integrated trace indicate zero levels of background activity corresponding to tonic discharge. $\boldsymbol{B}$, Histograms illustrating the relationship between preparations (proportions indicated in parentheses) producing fictive cervical locomotion during caudal pharmacological activation and thoracic barrier position. C, Cervical ventral root; L, lumbar ventral root. 
T2-3 barrier] (Fig. 4A3,B). In the latter cases, it is noteworthy that both the amplitude of cervical bursting and the level of background tonic activity were weaker compared with control whole-cord pharmacological activation (Fig. 4, compare A3 and $A 1)$. This presumably corresponded to differences between the experimental activation of the cervical generators by 5-HT/NMA/DA (Fig. 4A1) and the propriospinal action of the lumbar generators on their cervical counterparts via endogenous transmitter release in the absence of exogenous chemicals in the rostral cord region (Fig. 4A3).

In contrast, in a corollary experiment in which 5-HT/NMA/DA was now applied rostral to the thoracic barrier, the chemically activated cervical generators were never able to elicit lumbar locomotorrelated activity (Fig. 4A4), whatever the position of the barrier (T4, $n=5$ trials; T10, $n=5$ trials). Together, these observations confirm the existence of propriospinal coupling between lumbar and cervical generators, which is predominantly caudorostral in direction, and furthermore, the effectiveness of this ascending influence is enhanced with the number of thoracic segments exposed to caudal 5-HT/NMA/DA activation.

To characterize further this lumbar-tocervical coordination, a series of split-bath experiments was done in conjunction with pharmacological manipulation of synaptic transmission. Again, spinal cords $(n=12)$ were first activated with 5-HT/NMA/DA to obtain control fictive locomotor patterns (Fig. 5A1) with an out-of-phase coordination between the two sides (Fig. 5A2) (mean cross-correlation coefficient: bilateral C8 ventral roots, $-0.38 \pm 0.05$; bilateral L2 roots, $-0.64 \pm 0.02$ ) (Fig. $5 A 3)$. BIC $\left(0.25 \times 10^{-5} \mathrm{M}\right)$ and STR $\left(0.25 \times 10^{-5} \mathrm{M}\right)$ were then coapplied caudal to T7 while the entire spinal cord remained activated with 5-HT/NMA/DA. As a consequence of the selective blockade of caudal inhibitory GABA/glycinergic synapses (Bracci et al., 1996), slow synchronous bursting now occurred in the L2 roots of all 12 preparations, but unexpectedly, it also occurred in left-right C8, where inhibitory synapses were not exposed to the antagonists and therefore presumably remained functional (Fig. $5 B 1, B 2)$. This dramatic alteration to generalized synchronous bursting is reflected in the switch in sign of the crosscorrelation coefficients seen in Figure 5B3 (compare with A3), which now corresponded to an in-phase left-right coordination occurring at both caudal and ros-
A1

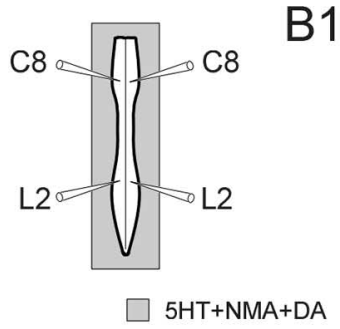

B1

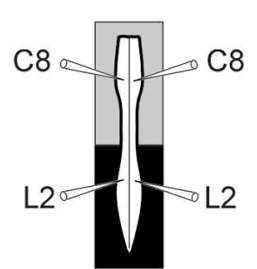

C1

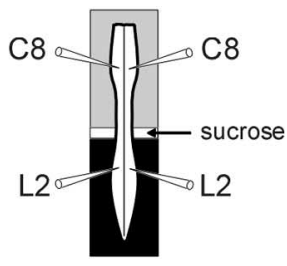

$5 \mathrm{HT}+\mathrm{NMA}+\mathrm{DA}+\mathrm{BIC}+\mathrm{STR}$
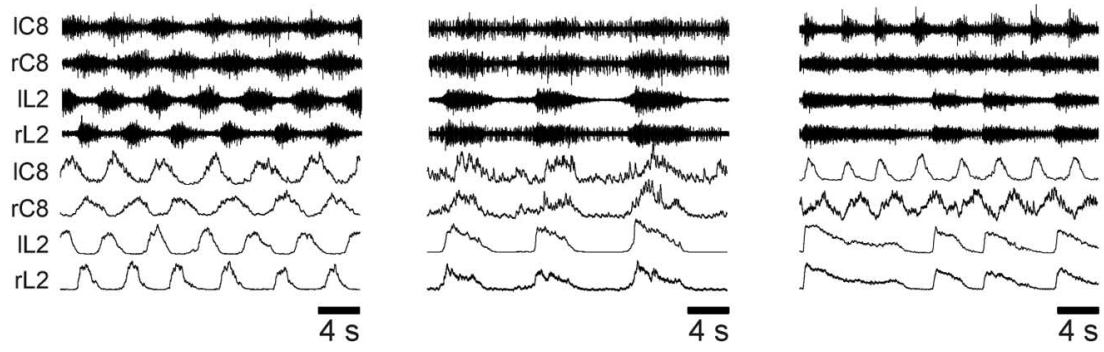

cuncrurr

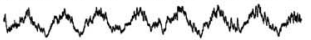
rommencm mom
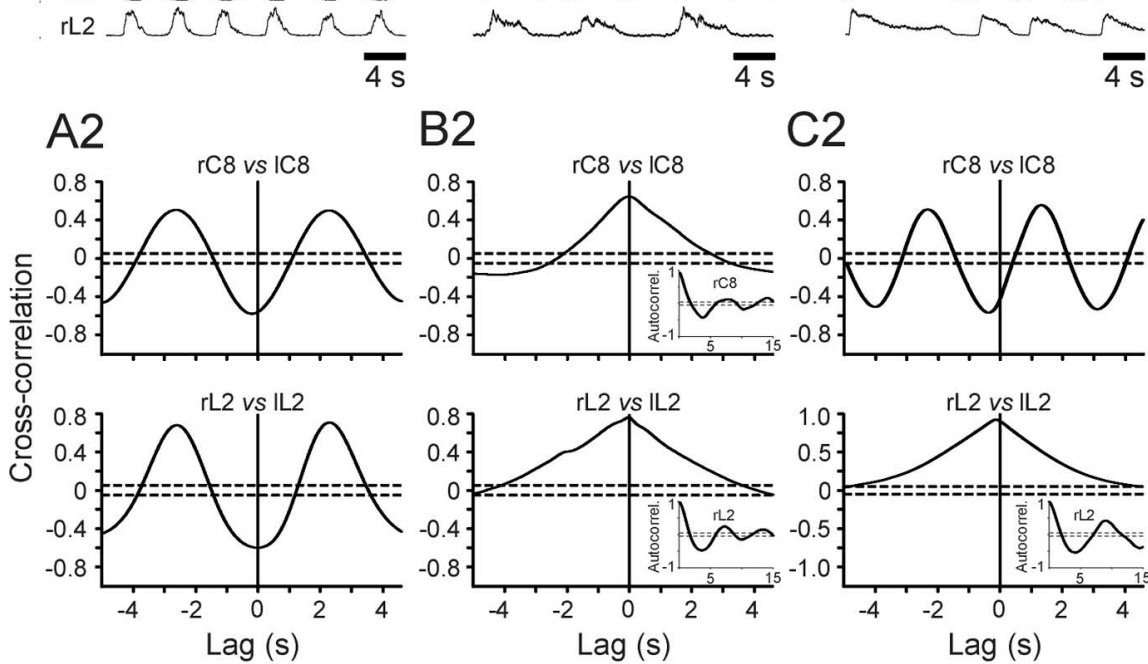

B2

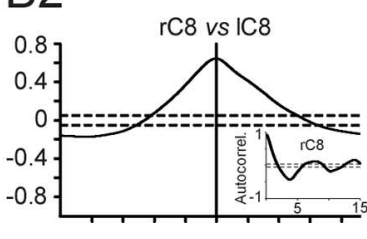

C2
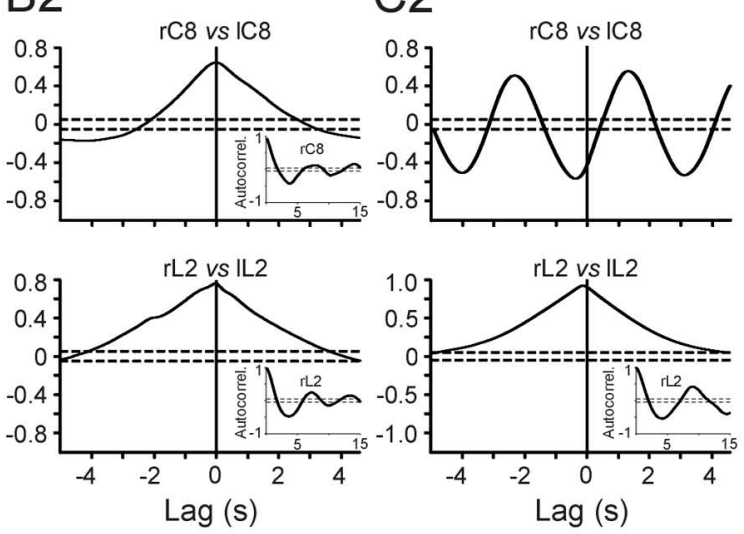

B3

C3

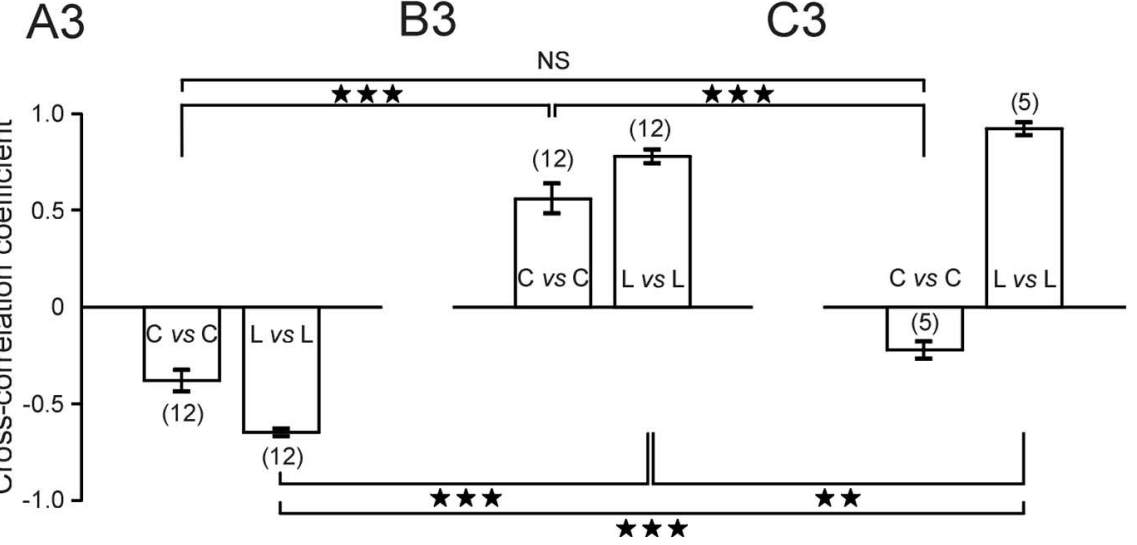

Figure 5. Caudorostral influence from lumbar to cervical generators in the absence of caudal synaptic inhibition. $\boldsymbol{A} \mathbf{1}, \mathbf{B 1}, \mathbf{C 1}$, Top, Schematics of experimental procedures; bottom, raw (upper) and integrated (lower) ventral root activity at cervical (bilateral (8) and lumbar (bilateral L2) levels during 5-HT/NMA/DA perfusion to the whole cord (A1) and (B1) when the spinal region caudal to T7 is additionally bathed with BIC $\left(0.25 \times 10^{-5} \mathrm{M}\right)$ and STR $\left(0.25 \times 10^{-5} \mathrm{M}\right)$. C1, Same saline conditions as in $B 1$ but after additional sucrose blockade of axonal conduction through thoracic spinal segments. $A 2, B 2, C 2$, Cross-correlograms (corresponding to $A 1, B 1, C 1$, respectively) showing strict alternation ( $A 2$, control conditions) and then synchronization ( $B 2$, during lumbar BIC plus STR application) between bilateral ventral roots at both lumbar (L2) and cervical (C8) levels. C2, Cross-cord cervical alternation was restored by thoracic cord conduction block, although the lumbar roots continued to burst in synchrony. Each cross-correlogram was computed from 120 to 190 s of activity; dashed lines indicate $95 \%$ ( \pm 2 SEM) confidence interval. Autocorrelograms occurring under BIC/STR are added as insets in $B \mathbf{2}$ and in the bottom of $\mathbf{C 2}$. A3, B3, C3, Mean cross-correlation coefficients ( \pm SEM) of left-right motor root activity at cervical $(C)$ and lumbar $(L)$ levels under control saline (A3), during caudal blockade of synaptic inhibition (B3), and after additional thoracic conduction block (C3). Numbers of preparations are indicated in parentheses. ${ }^{\star \star} p<0.01 ;{ }^{\star \star \star} p<0.001$. NS, Not significantly different. 
A1

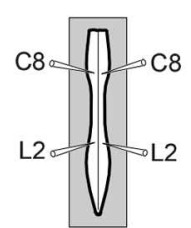

B1

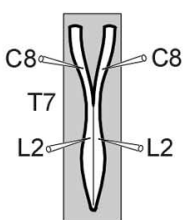

C1

$5 \mathrm{HT}+\mathrm{NMA}+\mathrm{DA}$

$5 \mathrm{HT}+\mathrm{NMA}+\mathrm{DA}+\mathrm{BIC}+\mathrm{STR}$

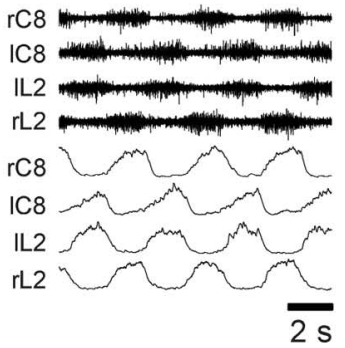

A2
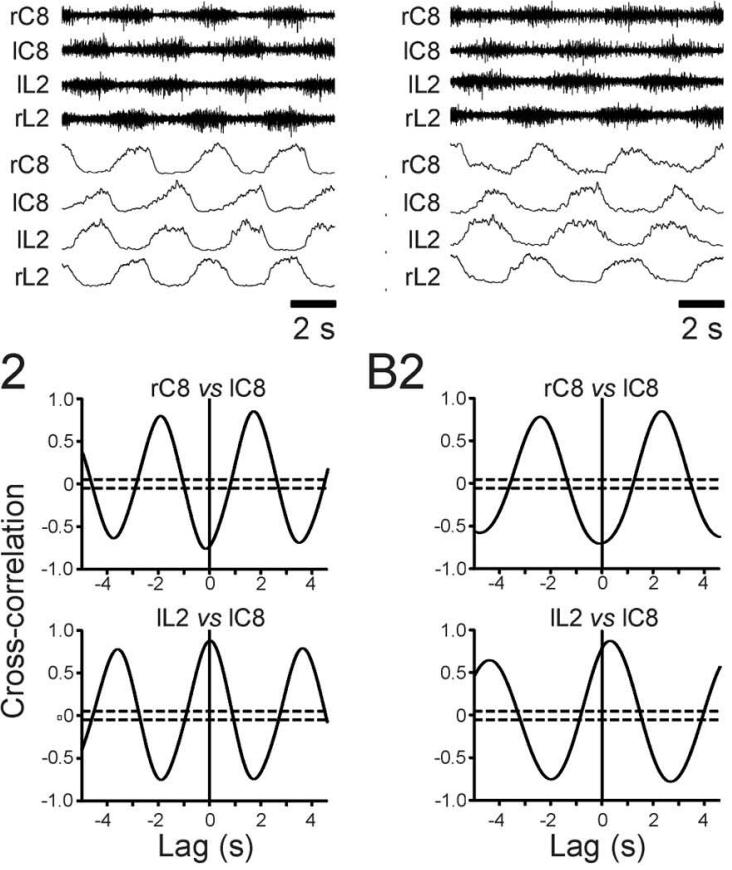

B2
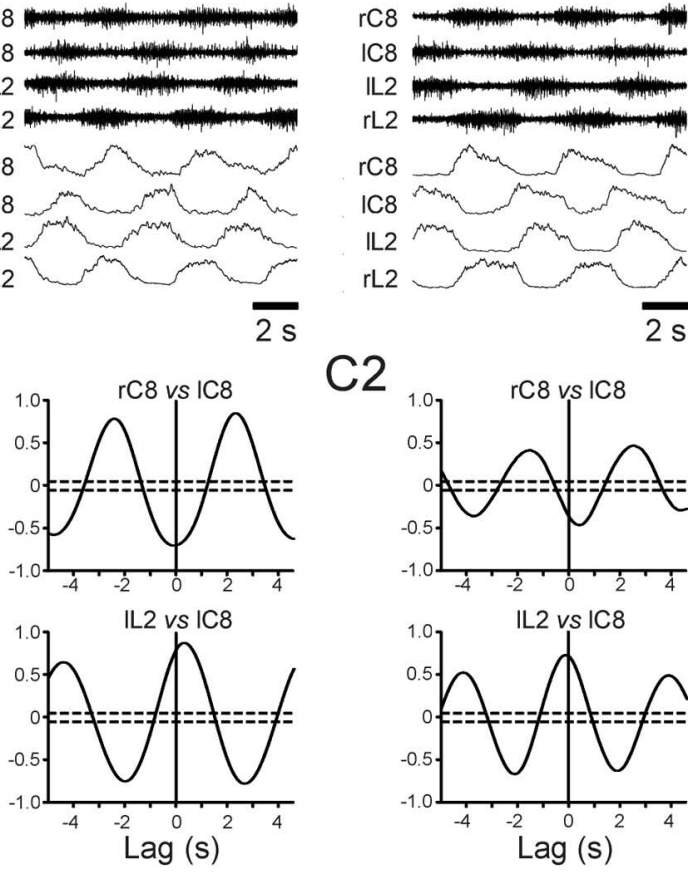

$\mathrm{C} 2$
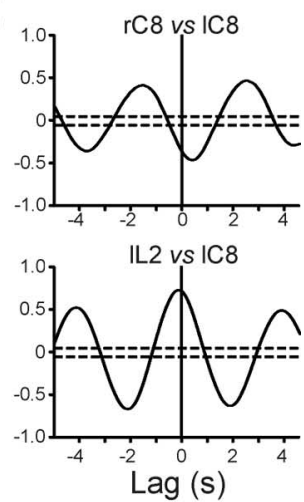

D1
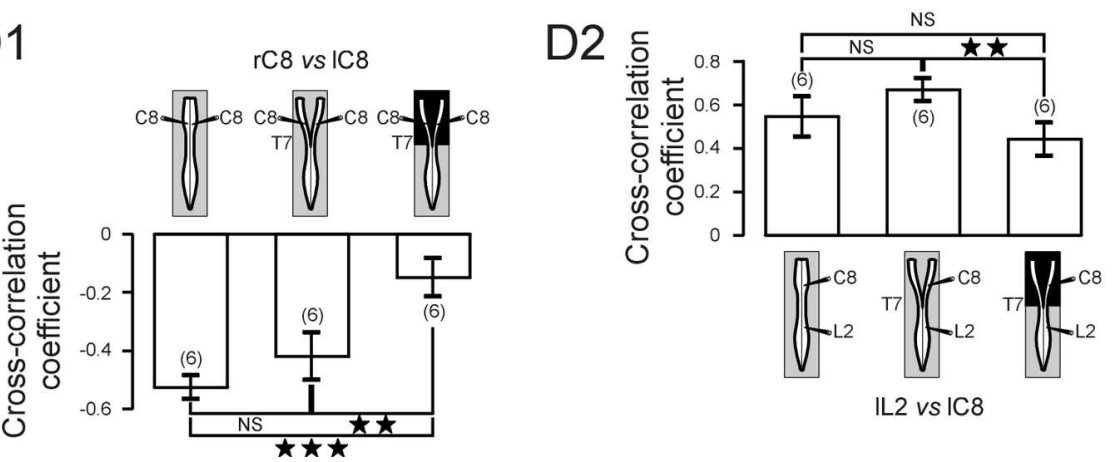

Figure 6. Involvement of ascending lumbar excitation in bilateral cervical alternation and caudorostral coordination. A1, B1, C1, Ventral root activity at cervical (bilateral (8) and lumbar (bilateral L2) levels during 5-HT/NMA/DA perfusion to the whole cord (A1), after a midsagittal lesion extending from C1 to T7 (B1), and when BIC plus STR was additionally applied to the cord anterior to $T 7$ (C1). A2, B2, C2, Corresponding cross-correlograms illustrating left-right cervical (C8 vs (8) and caudorostral (homolateral L2 vs (8) coordinations in control conditions (A2), after sagittal cervicothoracic lesion (B2), and then after rostral BIC plus STR application (C2). Sample size, 120-190 s. Dashed lines indicate 95\% ( \pm 2 SEM) confidence interval. $\boldsymbol{D}$, Mean cross-correlation coefficients ( \pm SEM) of right versus left cervical ventral root bursts (D1) and homolateral $L 2$ versus $(8$ (D2) motor bursts under the three different experimental conditions. Note that left-right alternation persisted at the cervical level despite longitudinal cord section and pharmacological blockade of cervical synaptic inhibition. Numbers of preparations are indicated in parentheses. $\star_{p}<0.01 ; \star \star \star p<0.001$. NS, Not significantly different.

tral spinal levels ( $\mathrm{L} 2$ ventral roots, $0.78 \pm 0.03$; C8 ventral roots, $0.56 \pm 0.07 ; p<0.001)$. It is also noteworthy that, under these conditions of lumbar inhibitory synaptic blockade, synchronous bursting also occurred in homolateral flexor (L2) and extensor (L5) ventral roots (data not shown). Finally, to verify that the synchronous cervical activity was indeed strictly a result of lum-

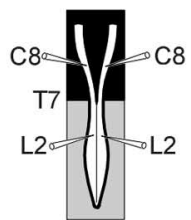

bar input, the two spinal regions (still under the same saline conditions) of five preparations were decoupled by a sucrose block placed at the intervening thoracic level (Fig. 5C1, schematic). This led to an immediate restoration of faster, bilaterally alternating activity at the cervical level (Fig. $5 \mathrm{Cl}$, top $\mathrm{C2}$, left histogram bars in C3), meaning that the lumbar generators were no longer able to impose their slower, still synchronously bursting rhythm on the cervical CPGs, which were now free to reexpress their inherent pattern-generating properties.

In assessing the extent to which lumbar locomotor circuitry can impose temporal patterning at the cervical level, we hypothesized that, under normal conditions, the bilateral alternation of cervical locomotor activity should be governed, at least in part, by alternating input from the lumbar generators. To test this idea, we examined the evolution of left-right and anteroposterior coordination in a 5-HT/NMA/DAinduced locomotor rhythm in six preparations in response to combined axial cord lesions in the rostral region and inhibitory synaptic blockade. Under control chemical activation (Fig. 6A1), the cervical and lumbar generators produced fictive locomotor rhythmicity with a typical out-ofphase coordination between C8 ventral roots (mean cross-correlation coefficient, $-0.53 \pm 0.04)$ (Fig. 6A2, left D1), whereas homolateral C8 and L2 roots remained inphase (mean cross-correlation coefficient, $0.55 \pm 0.09$ ) (Fig. 6A2, left D2). To suppress cervical cross-cord connectivity involved in bilateral C8 burst alternation, a midsagittal cord section was made, which extended from C1 to T7 (Fig. 6B1, schematic). Surprisingly, despite this surgical decoupling, an antiphase coordination persisted between the left and right $\mathrm{C} 8$ ventral roots (Fig. $6 \mathrm{B1}$ ), with the mean cross-correlation coefficient displaying a small but insignificant reduction (from $-0.42 \pm 0.08 ; p=0.236$ ) (Fig. 6B2, middle bar in D1). Similarly, the synchrony between homolateral C8 and L2 was also preserved (Fig. 6B1), showing a positive and statistically unaltered correlation coefficient $(0.67 \pm 0.05 ; p=0.101)$ from control (Fig. 6B2, middle bar in D2). Furthermore, when BIC/STR was added to a split-bath compartment that was set up rostral to T7 (Fig. 6C1, schematic), these phase relationships were still maintained (Fig. 6C1, C2), although the mean cross-correlation coefficients were significantly decreased (homologous C8 vs C8, $-0.15 \pm 0.06$; homolateral L2 vs C8, $0.44 \pm 0.08$ ) (Fig. 6, right D1, D2). These results therefore indicate that both inhibitory and excitatory synaptic pathways from the lumbar generators coordinate cervical locomotor pat- 
A1

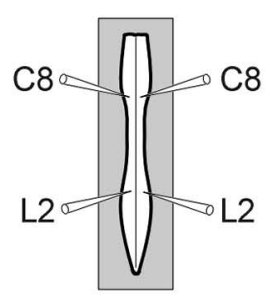

$5 \mathrm{HT}+\mathrm{NMA}+\mathrm{DA}$

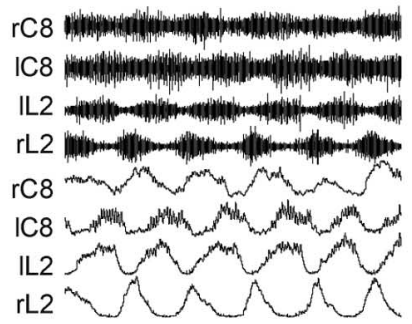

$\overline{2 s}$

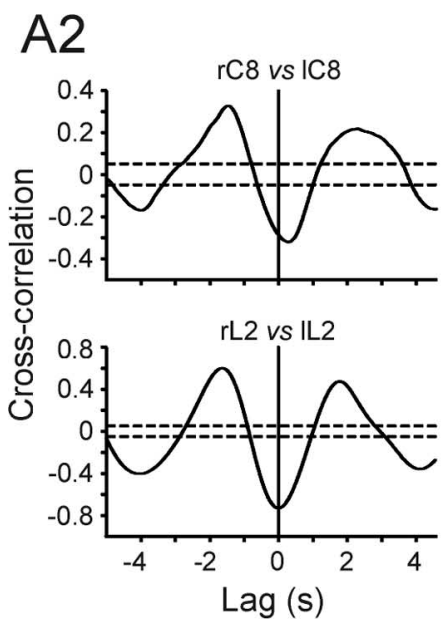

B2
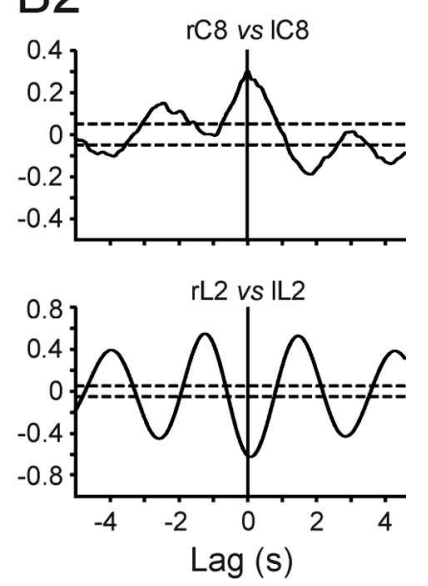

A3
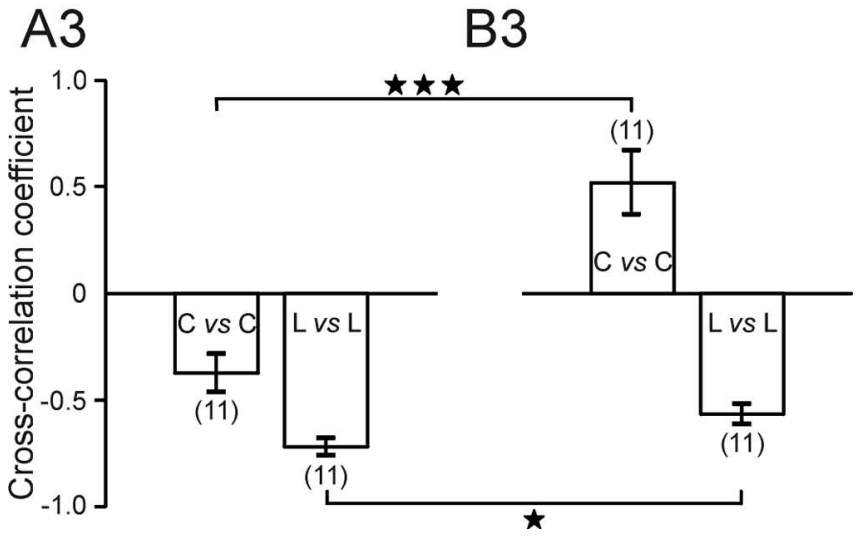

Figure 7. Lack of effect of blockade of cervical synaptic inhibition on bilateral lumbar rhythmicity. A1, B1, Ventral root activity at cervical (bilateral (8) and lumbar (bilateral L2) levels during 5-HT/NMA/DA perfusion of the whole cord (A1) and when BIC plus STR is added rostrally to T7. $\boldsymbol{A 2}, \boldsymbol{B} \mathbf{2}$, Cross-correlograms showing coordination between bilateral ventral roots at $C 8$ and L2 levels in control conditions (A2) and after rostral BIC plus STR application (B2). Note that left and right lumbar rhythmicity continues to alternate while cervical activity becomes bilaterally synchronized. C, Mean cross-correlation coefficients ( \pm SEM) of right versus left motor root activity. Numbers of preparations are indicated in parentheses. ${ }^{\star} p<0.05 ;{ }^{\star}{ }^{\star}{ }^{\star} p<$ 0.001 . terning, with ascending excitation playing a major role in both lumbocervical coupling and cervical left-right alternation.

In a final step, the contribution of any descending cervicolumbar influences to interlimb coupling was assessed in a corollary experiment to that of Figure 5, in which saline with BIC/STR was added to regions rostral to $\mathrm{T} 7$ of otherwise intact isolated cords $(n=11)$. Under these conditions, cervical left-right alternation in the activated control cord (Fig. 7A1) was replaced by synchronous bursting (Fig. 7B1) with an associated switch in sign of the mean correlation coefficient $(-0.37 \pm 0.08$ vs $0.52 \pm 0.15 ; p<$ 0.001 ) (Fig. 7, top $A 2, B 2$, left bars in $A 3, B 3$ ). Importantly, however, the phase relationships at the lumbar level remained unchanged, although the correlation coefficient was slightly but significantly decreased $(-0.72 \pm 0.04$ vs $-0.56 \pm 0.04 ; p<0.05)$ (Fig. 7, bottom $A 2, B 2$, right bars in $A 3, B 3$ ). It is also noteworthy that cross-correlation analysis revealed a complete lack of cervicolumbar coupling under these experimental conditions (data not shown). Therefore, these findings demonstrate that the cervical generators are unable to impose their rhythm structure on their lumbar counterparts.

\section{Discussion}

The findings of this study, which are summarized in Figure 8, show that the locomotor CPGs in the newborn rat spinal cord are interconnected principally via propriospinal neural circuitry that extends from rhythmogenic lumbar to cervical cord levels, involving a caudorostral excitability gradient that derives from a combination of ascending excitatory and inhibitory synaptic influences.

Fictive quadrupedal walking

Recordings from cervical and lumbar motor roots of the isolated spinal cord allowed coupling patterns between the networks that normally control forelimbs and hindlimbs to be compared with the coordination of actual quadrupedal movements in the freely behaving animal. The rhythmic locomotor-like activity recorded in vitro displayed a stereotyped diagonal coordination pattern that corresponded to the predominantly walking-like gait observed in vivo during both olfactory guided air stepping (Fig. 1 A) (Jamon and Clarac, 1998) and free swimming (Bekoff and Trainer, 1979) as well as following pharmacological induction by the intraperitoneal injection of L-DOPA (McEwen et al., 1997). In this way, flexor and extensor synergies occurred between homolateral cervical and lumbar motor bursts, which also fired in strict left-right alternation. It is important to remember that our in vitro experiments were performed on completely isolated spinal cords in the absence not only of movement-related proprioceptive feedback but also of the brainstem and other higher structures. Therefore, the coordination patterns seen were necessarily mediated solely by synaptic pathways that were intrinsic to the spinal cord, without the participation of more distributed sensorimotor and supraspinal circuitry, which also play an important role in forelimb-hindlimb coordination (English, 1989).

\section{Coordination of independent cervical and lumbar CPGs}

In the present study, the use of a localized thoracic axonalconduction block to decouple the cervical and lumbar generators unmasked separate cervical rhythmicity, which was clearly locomotor-like in terms of its bilateral alternation, burst duration, and cycle frequency (Figs. 2, 3A). The similarity in cycle frequency of the independent cervical and lumbar generators after sucrose-block separation was unexpected in light of findings reported previously (Ballion et al., 2001) (Fig. 3B), in which cervical rhythmicity expressed after thoracic cord transection was 

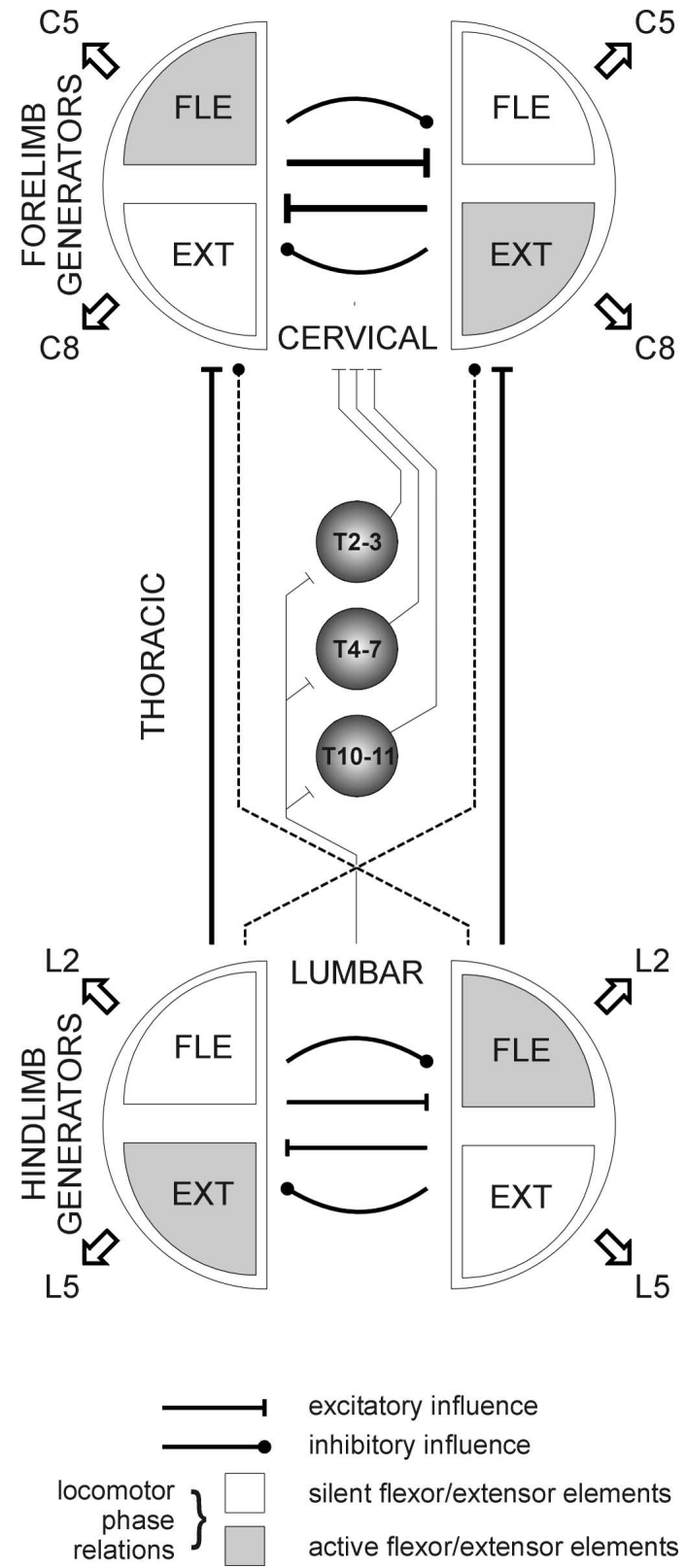

Figure 8. Summary of central spinal pathways contributing to interlimb coordination in quadrupedal locomotion. See Discussion for an explanation. EXT, Extensor; FLE, flexor; T, thoracic segment.

considerably slower than in the intact cord. Although uncertainty remains as to whether the slow, isolated cervical rhythm with prolonged motor bursts corresponded to actual forelimb locomotion (Cowley et al., 2003), our sucrose-block experiments suggest that forelimb locomotor network rhythmogenesis is inherently stronger than previously thought. This, in turn, indicates that thoracic-cord sectioning disrupts the functional integrity of cervical rhythm-generating circuitry and warns against using mechanical lesions alone to assess the modular rhythm-generating capability of spinal circuitry.

Coordination between cervical and lumbar generators is asymmetrical in the sense that rhythmically active lumbar generators can drive their cervical counterparts in the absence of pharmacological activation at the cervical level but not vice versa (Fig. 4). Importantly, moreover, the use of different barrier positions to separate rostral spinal regions from 5-HT/NMA/DA-activated caudal regions disclosed an ascending lumbar influence on the cervical generators, which increased as a function of the number of drug-exposed thoracic segments. This demonstrates that the thoracic segments are not simply passive conveyors of phasic information from more caudal cord regions but are themselves constitutive elements of a more distributed, rostrally projecting network that is rhythmically active with the lumbar generators. Although the segmental thoracic circuitry is itself not rhythmogenic (Ballion et al., 2001), it evidently undergoes increased excitability in the presence of 5-HT/NMA/DA. Such thoracic region activation, in combination with presumed direct, feedforward axonal projections from each thoracic segment to the cervical region (Fig. 8), indicates a caudorostral excitability gradient that, with sufficient actively participating segments, could drive bilaterally alternating rhythmicity at the nondrugexposed cervical level (Fig. 4A3).

The active contribution of intervening thoracic segments to caudorostral coordination invites comparison with evolutionaryprimitive, metamerically segmented vertebrates such as lamprey, frog larvae, and the newt, in which body undulations during swimming are driven by segmentally distributed chains of coupled oscillators that are appropriately coordinated by gradients of neuronal excitability extending progressively along the cord (Matsushima and Grillner, 1992; Tunstall and Roberts, 1994; Delvolvé et al., 1997). However, a fundamental difference is that in these lower vertebrate classes, all coupled segments contribute equally to body propulsion, whereas in quadruped mammals, thoracic cord circuitry uses locomotor and other synaptic drives to produce compensatory movements by axial musculature during a variety of behaviors, including locomotion (Gramsbergen et al., 1999; Cazalets and Bertrand, 2000). However, in fast-running feline mammals, thoracic muscles contribute actively to limbbased propulsion (Hildebrand, 1961), although here, trunk movements are generated by alternating dorsoventral contractions (Koehler et al., 1984).

\section{Pathways mediating lumbar-thoracic control of cervical generators}

The extent to which the lumbar generators can influence their cervical partners was particularly evident in experiments in which the left-right coordination of lumbar rhythmicity was selectively altered by pharmacological manipulation. Blockade of synaptic inhibition in the caudal region produced a single, in-phase lumbar rhythm (Cowley and Schmidt, 1995; Bracci et al., 1996) that was also able to drive bilaterally synchronous cervical rhythmicity, despite the maintenance of cross-cord inhibitory connections (see below) that would normally ensure bilateral cervical alternation (Fig. 5). Conversely, the ability of the lumbar generators alone to impose left-right alternation between the cervical generators was revealed by mechanically decoupling the latter with a midsagittal section of the rostral cord region under conditions of whole-cord chemical activation (Fig. 6). This caudorostral drive appeared to be mediated principally by homolateral excitatory pathways, because the coordination persisted after additional blockade of synaptic inhibition in the sectioned cervical cord region. However, a slight but significant decrease in the cervical cross-cord coupling coefficient indicated that ascending (possibly diagonal) inhibitory lumbar influences were also involved. Together, therefore, these results suggest that in the newborn rat, a combination of excitatory and inhibitory propriospinal pathways mediate interlimb coordination, with rostrally projecting excitation, in particular, serving both to maintain forelimb- 
hindlimb coupling and to reinforce left-right forelimb alternation.

Evidence that left-right forelimb coupling, as for the hindlimb generators (Cowley and Schmidt, 1997; Butt et al., 2002), involves a combination of local reciprocal inhibition and excitation, derived from the switch seen from bilateral alternation to synchrony after blockade of all cervical synaptic inhibition in the chemically activated intact cord (Fig. 7) (Ho, 1997). Under these conditions, however, the lumbar generators were now unable to impose bilateral alternation at the cervical level, indicating that ascending excitation alone was insufficient to counteract the remaining cross-cord excitation in the rostral cord. Finally, it is noteworthy that a bilaterally synchronous cervical rhythm was unable, in a reciprocal manner, to force an in-phase lumbar pattern (Fig. 7), further indicating a substantially weaker descending influence from the cervical to lumbar generators.

A similar dominance of the lumbar generators over their cervical counterparts was previously reported in the spinal rabbit (Viala and Vidal, 1978), in which labile forelimb locomotor rhythmicity was found to be driven by more robust hindlimb network activity. In the neonatal rat spinal cord, however, the similarity in frequencies of the independent cervical and lumbar generators seen after sucrose-block separation suggests that, here, phase coordination between lumbar and cervical locomotor circuitry derives principally from a caudorostral asymmetry in coupling pathways between the two spinal levels rather than from a "trailing oscillator" configuration (Matsushima and Grillner, 1992), in which lumbar oscillators with an intrinsically higher rhythmogenic capacity entrain their less excitable cervical partners. It is also relevant here that earlier in the developing rat spinal cord, the pathways mediating lumbocervical coupling appear to become functional after the lumbar (Nishimaru and Kudo, 2000) and cervical CPG circuits, because uncoordinated rhythmic forelimb and hindlimb movements can occur in the late embryonic animal (Bekoff and Lau, 1980).

The anatomical pathways mediating lumbocervical coordination remain to be identified, although long ascending propriospinal pathways that are presumed to ensure hindlimb-forelimb coordination have been identified in cat spinal columns (English et al., 1985). More recently, a population of so-called "longrange" commissural interneurons has been identified in neonatal rat, which cross the lumbar cord, have ascending contralateral axons (Eide et al., 1999; Stokke et al., 2002), and serve to coordinate bilateral hindlimb locomotor activity (Butt and Kiehn, 2003). However, that the axons of these lumbar interneurons extend to a maximum of only six segments from their segment of origin (Birinyi et al., 2003), at most, renders them potential candidates for the first stage of an indirect, local-circuit pathway to the cervical cord.

\section{Wider implications}

Establishing the neural substrates of interlimb coordination in quadruped animal models also offers important insights into locomotor neural substrates of bipedal primates (Wannier et al., 2001; Dietz, 2002), with consequent clinical implications (Dietz et al., 1999; Taub et al., 2002). Of particular relevance is the finding that basic neural mechanisms in bipeds and quadrupeds are shared, including spinal CPG circuitry (Dietz, 2002) and propriospinal pathways that coordinate cervical and lumbar networks controlling upper and lower limb movements during locomotion (Nathan et al., 1996). In this context, furthermore, it is interesting that in spinal cord-injured humans, the capacity to re-express normal locomotor movement increases with the level of spinal lesion (Dietz et al., 1999), indicating that the neuronal circuitry underlying bipedal locomotor rhythmicity is not restricted to a specific spinal region but extends from lumbar through to cervical levels. This is also consistent with our observations in the neonatal rat, in which the degree of coupling between hindlimb and forelimb locomotor-generating networks is enhanced as the functional integrity of thoracolumbar circuitry is increased in the rostral direction.

\section{References}

Ballion B, Morin D, Viala D (2001) Forelimb locomotor generators and quadrupedal locomotion in the neonatal rat. Eur $\mathrm{J}$ Neurosci 14:1727-1738.

Barrière G, Mellen N, Cazalets JR (2004) Neuromodulation of the locomotor network by dopamine in the isolated spinal cord of newborn rat. Eur J Neurosci 19:1325-1335.

Bekoff A, Lau B (1980) Interlimb coordination in 20-day-old rat fetuses. J Exp Zool 214:173-175.

Bekoff A, Trainer W (1979) The development of inter-limb co-ordination during swimming in postnatal rats. J Exp Biol 83:1-11.

Birinyi A, Viszokay K, Weber I, Kiehn O, Antal M (2003) Synaptic targets of commissural interneurons in the lumbar spinal cord of neonatal rats. J Comp Neurol 461:429-440.

Bracci E, Ballerini L, Nistri A (1996) Localization of rhythmogenic networks responsible for spontaneous bursts induced by strychnine and bicuculline in the rat isolated spinal cord. J Neurosci 16:7063-7076.

Brocard F, Vinay L, Clarac F (1999) Development of hindlimb postural control during the first postnatal week in the rat. Dev Brain Res 117:81-89.

Butt SJ, Kiehn O (2003) Functional identification of interneurons responsible for left-right coordination of hindlimbs in mammals. Neuron 38:953-963.

Butt SJ, Lebret JM, Kiehn O (2002) Organization of left-right coordination in the mammalian locomotor network. Brain Res Brain Res Rev 40:107-117.

Cazalets JR, Bertrand S (2000) Ubiquity of motor networks in the spinal cord of vertebrates. Brain Res Bull 53:627-634.

Cazalets JR, Sqalli-Houssaini Y, Clarac F (1992) Activation of the central pattern generators for locomotion by serotonin and excitatory amino acids in neonatal rat. J Physiol (Lond) 455:187-204.

Cazalets JR, Borde M, Clarac F (1995) Localization and organization of the central pattern generator for hindlimb locomotion in newborn rat. J Neurosci 15:4943-4951.

Cowley KC, Schmidt BJ (1995) Effects of inhibitory amino acid antagonists on reciprocal inhibitory interactions during rhythmic motor activity in the in vitro neonatal rat spinal cord. J Neurophysiol 74:1109-1117.

Cowley KC, Schmidt BJ (1997) Regional distribution of the locomotor pattern-generating network in the neonatal rat spinal cord. J Neurophysiol 77:247-259.

Cowley KC, Zaporozhets E, Schmidt BJ (2003) Influence of the thoracolumbar region on locomotor and non-locomotor rhythm generation in vitro neonatal rat spinal cord. Soc Neurosci Abstr 29:277.10.

Delvolvé I, Bem T, Cabelguen J-M (1997) Epaxial and limb muscle activity during swimming and terrestrial stepping in the adult newt, Pleuodeles waltl. J Neurophysiol 78:638-650.

Dietz V (2002) Do human bipeds use quadrupedal coordination? Trends Neurosci 25:462-467.

Dietz V, Nakazawa K, Wirz M, Erni T (1999) Level of spinal cord lesion determines locomotor activity in spinal man. Exp Brain Res 128:405-409.

Eide AL, Glover J, Kjaerulff O, Kiehn O (1999) Characterization of commissural interneurons in the lumbar region of the neonatal rat spinal cord. J Comp Neurol 403:332-345.

English AW (1979) Interlimb coordination during stepping in the cat: an electromyographic analysis. J Europhysiol 42:638-650.

English AW (1989) Interlimb coordination during locomotion. Am Zool 29:255-266.

English AW, Tigges J, Lennard PR (1985) Anatomical organization of long ascending propriospinal neurons in the cat spinal cord. J Comp Neurol 240:349-358

Gramsbergen A, Geisler HC, Taekema H, van Eykern LA (1999) The activation of back muscles during locomotion in the developing rat. Brain Res Dev Brain Res 112:217-228. 
Grillner S (1981) Control of locomotion in bipeds, tetrapods and fish. In: Handbook of physiology, Sec 2. The nervous system (Brookhardt JM, Mountcastle VB, eds), pp 1179-1236. Bethesda, MD: American Physiological Society.

Hildebrand M (1961) Further studies on the locomotion of the cheetah. J Mammal 42:84-89.

Ho SM (1997) Rhythmic motor activity and interlimb co-ordination in the developing pouch young of a wallaby (Macropus eugenii). J Physiol (Lond) 501:623-636.

Jamon M, Clarac F (1998) Early walking in the neonatal rat: a kinematic study. Behav Neurosci 112:1218-1228.

Juvin L, Nargeot R, Morin D (2003) Central and sensory mechanisms underlying intersegmental coordination in quadrupedal fictive locomotion. Soc Neurosci Abstr 29:277.18.

Kiehn O, Butt SJ (2003) Physiological, anatomical and genetic identification of CPG neurons in the developing mammalian spinal cord. Prog Neurobiol 70:347-361.

Kjaerulff O, Kiehn O (1996) Distribution of networks generating and coordinating locomotor activity in the neonatal rat spinal cord in vitro: a lesion study. J Neurosci 16:5777-5794.

Koehler WJ, Schomburg ED, Stephens H (1984) Phasic modulation of trunk muscles afferents during fictive spinal locomotion in cats. J Physiol (Lond) 353:187-197.

Kremer E, Lev-Tov A (1997) Localization of the spinal network associated with generation of hindlimb locomotion in the neonatal rat and organization of its transverse coupling system. J Neurophysiol 77:1155-1170.

Marder E, Calabrese RL (1996) Principles of rhythmic motor pattern generation. Physiol Rev 76:687-717.

Matsushima T, Grillner S (1992) Neural mechanisms of intersegmental coordination in lamprey: local excitability changes modify the phase coupling along the spinal cord. J Neurophysiol 67:373-388.

McEwen ML, Van Hartesveldt C, Stehouwer DJ (1997) L-DOPA and quipazine elicit air-stepping in neonatal rats with spinal cord transections. Behav Neurosci 111:825-833.

McKenna JE, Prusky GT, Whishaw IQ (2000) Cervical motoneuron topog- raphy reflects the proximodistal organization of muscles and movements of the rat forelimb: a retrograde carbocyanine dye analysis. J Comp Neurol 419:286-296.

Nathan PW, Smith M, Deacon P (1996) Vestibulospinal, reticulospinal and descending propriospinal nerve fibres in man. Brain 119:1809-1833.

Navarrete R, Slawińska U, Vrbová G (2002) Electromyographic activity patterns of ankle flexor and extensor muscles during spontaneous and L-DOPA-induced locomotion in freely moving neonatal rats. Exp Neurol 173:256-265.

Nishimaru H, Kudo N (2000) Formation of the central pattern generator for locomotion in the rat and mouse. Brain Res Bull 53:661-669.

Orlovsky GN, Deliagina TG, Grillner S (1999) Quadrupedal locomotion in mammals. In: Neuronal control of locomotion: from mollusc to man (Orlovsky GN, Deliagina, TG, Grillner S, eds), pp 154-246. New York: Oxford UP.

Rossignol S (1996) Neural control of stereotypic limb movements. In: Handbook of physiology, Sec 12. Exercise: regulation and integration of multiple movements (Rowell RB, Shepherd JT, eds), pp 173-216. Bethesda, MD: American Physiological Society.

Stein PSG, Grillner S, Selverston AI, Stuart DG (1997) Neurons, networks, and motor behavior. Cambridge, MA: MIT.

Stokke MF, Nissen UV, Glover JC, Kiehn O (2002) Projection patterns of commissural interneurons in the lumbar spinal cord of the neonatal rat. J Comp Neurol 446:349-359.

Taub E, Uswatte G, Elbert T (2002) New treatments in neurorehabilitation founded on basic research. Nat Rev Neurosci 3:228-236.

Tunstall MJ, Roberts AA (1994) Longitudinal gradient of synaptic drive in the spinal cord of Xenopus embryos and its role in co-ordination of swimming. J Physiol (Lond) 474:393-405.

Viala D, Vidal C (1978) Evidence for distinct spinal locomotion generators supplying respectively fore- and hindlimbs in the rabbit. Brain Res 155:182-186.

Wannier T, Bastiaanse C, Colombo G, Dietz V (2001) Arm to leg coordination in humans during walking, creeping and swimming activities. Exp Brain Res 141:375-379. 